\title{
Increase of the Ventricular Fibrillation Threshold by 711389-S, a New Antiarrhythmic Agent, in Guinea-Pigs
}

\author{
Shigeyuki NAKAJIMA and Motohiko UEDA \\ Department of Pharmacology. Shionogi Research Laboratores. \\ Shionogi \& Co., Ltd. Fukushima-ku, Osaka 553, Japan
}

Accepted May 21. 1985

\begin{abstract}
The increase of the ventricular fibrillation threshold (VFT) by 711389-S, a new antiarrhythmic agent. was compared with several other antiarrhythmic drugs using both in vitro (Langendorff) and in vivo preparations of guinea-pigs. The doses of antiarrhythmic drugs for increasing VFT by 10 volts in in vitro ( $/ \mathrm{g})$ and in vivo $(\mathrm{mg} / \mathrm{kg}$. i.v.) preparations were as follows: 711389-S: 4.2, 0.15; disopyramide: 32.6. 0.86; quinidine: 32.0. 0.57; aprindine: 7.6. 0.55; propranolol: 16.6, 0.57 ; and lidocaine: $20.7,1.52$. The duration of the antifibrillatory effects of 711389 $\mathrm{S}$ almost corresponded with those of aprindine and propranolol.
\end{abstract}

Intravenous or oral administration of 711389-S (1-[1-\{2-(3-isopropylamino- 2 hydroxypropoxy)-3,6-dichlorophenyl $\}$ vinyl] - $1 \mathrm{H}$-imidazole) markedly inhibits aconitine arrhythmias in mice, ouabain arrhythmias in guinea-pigs and dogs, and ischemic arrhythmias in dogs (1). An electrophysiological study of 711389-S using isolated guinea-pig papillary muscles showed that it mainly suppressed the maximal upstroke velocity of action potentials, and the use-dependency resembled that of disopyramide rather than that of lidocaine (2). Thus, 711389-S was classified as a class la antiarrhythmic agent. The present study compared the effect of 711389-S on the ventricular fibrillation threshold (VFT) with those of other antiarrhythmic drugs using both in vitro and in vivo guinea-pig preparations.

Guinea-pig heart, isolated from males weighing $440-720 \mathrm{~g}$. was perfused by the Langendorff method with Krebs-Ringer bicarbonate solution containing $0.5 \%$ defibrinated blood gassed with $95 \% \mathrm{O}_{2}$ and $5 \%$ $\mathrm{CO}_{2}$, at a pressure of about $50 \mathrm{~cm} \mathrm{H}_{2} \mathrm{O}$ at $37^{\circ} \mathrm{C}$. A piece of string was passed through the ventricular apex and connected to a force displacement transducer (SB-1T, Nihon Kohden), by which the contractile tension was recorded on one channel of a polygraph (RM150. Nihon Kohden). Two platinum electrodes were placed on the anterior surface of the base of the ventricles to record the action potential on a second channel of the polygraph. The heart was stimulated through another two platinum electrodes attached to the posterior surface of the left ventricle. Rectangular pulses were generated by an electrical stimulator (MSE-3. Nihon Kohden). VFT was determined by applying serial rectangular impulses of $3 \mathrm{msec}$ duration at a frequency of $20 \mathrm{~Hz}(3,4)$, and the stimulating inten:ity was automatically increased at approximately $1 \mathrm{volt} / \mathrm{sec}$. As soon as the VFT was determined, the stimulation was stopped. The minimal voltage required to induce ventricular fibrillation was taken as the VFT.

Male guinea-pigs weighing 590-830 g were anaesthetized with peritobarbital- $\mathrm{Na}$ (25 $\mathrm{mg} / \mathrm{kg}$, i.p.) and urethane $(0.6 \mathrm{~g} / \mathrm{kg}$. s.c.). For electrical stimulation of the right ventricle, a bipolar catheter (external diameter. $0.9 \mathrm{~mm}$ ) was introduced into it via the right jugular vein $(5,6)$; the catheter position was confirmed by the action potential derived from it (7). The lead I electrocardiogram and femoral blood pressure were recorded on the polygraph. Trains of pulses $(50 \mathrm{~Hz}, 1$ or 3 msec) were applied between the left thigh and the right ventricle with an electrical stimulator (SEN-7103, Nihon Kohden). The stimulating intensity was automatically in- 
creased at approximately 1.1 volts/sec to determine the VFT, and the effects of intravenous administration of several drugs were observed. Electrical stimulation was stopped when the VFT was attained. When a VFT was above 40 volts, it was estimated as 40 volts. If the sinus rhythm was not observed within $30 \mathrm{sec}$ after electrical stimulation was stopped, the normal rhythm was restored with an electrical defibrillator (TEC-2101. Nihon Kohden). At the end of each experiment, the position of the stimulating electrode was checked after thoracotomy. The following reference antiarrhythmic drugs were used: disopyramide (Chugai). quinidine sulfate (Nakarai), aprindine hydrochloride (A. Christiams,) lidocaine hydrochloride (Fujisawa), and propranolol hydrochloride (Sigma).

In the isolated heart, 711389-S and other antiarrhythmic drugs dose-dependently increased the VFT. Disopyramide and other antiarrhythmic drugs showed parallelism of their dose-response curves, but not 711389 $\mathrm{S}$. The relative potencies $(95 \%$ confidence limits) of quinidine, aprindine, propranolol and lidocaine against disopyramide were 1.01 $(0.44-2.29), 4.23(2.39-7.91), 1.99(1.19-$ $3.42)$ and $1.44(0.46-6.28)$, respectively. Doses for increasing VFT by 10 volts (VFT 10 , ".g) were: 4.2 for $711389-5 ; 32.6$ for disopyramide: 32.0 for quinidine: 7.6 for aprindine: 16.6 for propranolol; and 20.7 for lidocaine. The antifibrillatory effects of 711389-S lasted for no less than $5 \mathrm{~min}$ at a dose of $10 \mathrm{~kg}$. As for the heart rate and contractile tension, 711389-S did not show any significant effects at the doses used.

In anaesthetized guinea-pigs, 711389-S significantly increased VFT at above $0.3 \mathrm{mg} /$ $\mathrm{kg}$. The antifibrillatory effects lasted for 20 $\mathrm{min}$ at $1 \mathrm{mg} / \mathrm{kg}$. Significant antifibrillatory effects of lidocaine, quinidine, disopyramide. propranolol and aprindine were observed at $1 \mathrm{mg} / \mathrm{kg}$ (Fig. 2). The dose-response curve of disopyramide paralleled those of the other drugs. The relative potencies $(95 \%$ confidence limit) against disopyramide of $711389-5$, quinidine, aprindine, propranolol and lidocaine were $6.34(2.97-17.81), 2.47$ $(0.81-9.79) .1 .85(1.06-3.62) .1 .66(0.82-$ 3.89 ) and $0.59(0.24-1.22)$, respectively. The



Fig. 1. Comparison of the antifibrillatory effects of several antiarrhythmic drugs in isolated guinea-pig hearts. After the ventricular fibrillation threshold (VFT) had been stabilized, these drugs were administered into the perfusing solution at the aortic cannula. The VFTs were determined before and at 1, 3, 5, 10. 15 min after drug administration. The mean absolute VFTs bctore 711389-S, disopyramide, quinidine. aprindine, propranolol and lidocaine administrations were $6.9 \pm 0.6 \mathrm{~V}(n=15), 6.4 \pm 0.4 \mathrm{~V}(n=12), 4.0 \pm 0.4$ $V(n=12) .8 .2 \pm 0.5 \vee(n=12), 5.3 \pm 0.4 \vee(n=8)$ and $4.6 \pm 0.6 \mathrm{~V}(n=12)$, respectively. The maximal $V F T$ increases were plotted. Each point represents the mean \pm S.E. "Significantly different from control VFTs at $P<0.001$ : ${ }^{b} P<0.01$ : " $P<0.05 . \triangle .711389-S$ $(n=5) ; 1$.$\rfloor disopyramide (n=5) ; 0$, quinidine $(n=4)$; - aprindine $(n=4)$ : $\boldsymbol{\nabla}$, propranolol $(n=4): 0$. lidocaine $(n=4)$.

$\mathrm{VFT}_{10}(\mathrm{mg} / \mathrm{kg})$ of $711389-\mathrm{S}$, disopyramide. quinidine, aprindine, propranolol and lidocaine were $0.15,0.86,0.57,0.55,0.57$ and 1.52 , respectively. As $711389-\mathrm{S}$ has a larger molecular weight (370) than the other drugs, its antifibrillatory effect was the most potent on the in vivo as well as in vitro preparations when compared on the bases of both the actual amount and the molecular weight.

The therapeutic indexes calculated from these VFT 10 in Vivo and LD50 (i.V.) in mice [711389-S, $19.8 \mathrm{mg} / \mathrm{kg}$; disopyramide, 30 $\mathrm{mg} / \mathrm{kg}$; quinidine, $53.6 \mathrm{mg} / \mathrm{kg}$ (1)] were $132.0,34.9$ and 94.0 for $711389-\mathrm{S}$, disopyramide and quinidine, respectively. Therefore, 711389-S seemed to have a wider safety margin than disopyramide and quinidine. which are both class la antiarrhythmic drugs. Electrical stimulation of 




Fig. 2. Comparison of the antifibrillatory effects of several antiarrhythmic drugs in anaesthetized guinea pigs. The VFTS were determined just before and at 1 . 5. 10,15, 20,30 min after intravenous drug administration. The mean absolute VFTs before 711389 -S, disopyramide, quinidine, aprindine, propranolol and lidocaine administration were $6.0 \pm 0.4 \mathrm{~V}(n=15)$, $7.6 \pm 0.8 \vee(n=12), 5.8 \pm 0.5 \vee(n=15), 5.9 \pm 0.4 \vee$ $(n=15), 7.0 \pm 0.5 \vee(n=15)$ and $6.7 \pm 0.4 \vee(n=15)$ respectively. The maximal VFT increases were plotted. Each point represents the mean \pm S.E. : Significantly different from control VFTs at $P<0.001$. " $P<0.01$; " $P<0.05$. $\triangle$. 711389-S $(n=5)$. disopyramide $(n=4)$; quinidine $(n=5)$; aprindine $(n=5)$ : $\boldsymbol{\nabla}$, propranolol $(n=5)$ : lidocaine $(n=5)$.

$20 \mathrm{~Hz}$ and $50 \mathrm{~Hz}$ might release noradrenaline and acetylcholine from nerve endings. However, the increase of VFT by 711389 - $S$ is presumed to be due to its stabilizing effect on the plasma membrane. since the $\beta$ adrenoceptor blocking and anticholinergic activities of $711389-\mathrm{S}$ are 1/2000-1/4000 of those of propranolol and about $1 / 4$ of those of disopyramide. Since sudden coronary death could be intimately related with the occurrence of ventricular fibrillation (8), the potent and lasting antifibrillatory effects of 711389-S, compared with other antiarrhythmic drugs, are of interest.

Acknowledgement: We would like to express our thanks to Mr. M. Nakamura, Department of Technology. Shionogi Research Laboratories. for modifying the continuous delivery system of the electrical stimulator.

\section{References}

1 Ogata, M., Matsumoto, H., Takahashi, K., Shimizu, S., Kida, S., Ueda, M., Kimoto, S. and Haruna, $M$ : Synthesis and antiarrhythmic activity of new 1-[1-[2-[3-(alkylamino)-2hydroxypropoxy] phenyl] vinyl]-1 $\mathrm{H}$-imidazoles and related compounds. J. Med. Chem. 27, 1142-1149 (1984)

2 Ninomiya, M., Toyama, J., Kodama, I. and Yamada, K.: Electrophysiological effects of 711389-S, a new antiarrhythmic agent on guinea-pig isolated cardiac muscle. J. Cardiovasc. Pharmacol. 6, 1222-1229 (1984)

3 Almotrefi, A.A. and Baker, J.B.E.: The antifibrillatory potency of aprindine, mexiletine. tocainide and lignocaine compared on Langendorff-perfused hearts of rabbits and guneapigs. J. Pharm. Pharmacol. 32, 746-750 (1980)

4 Almotrefi, A.A. and Baker, J.B.E.: Antifibrillatory efficacy of encainide. lorcainide and ORG 6001 compared with lignocaine in isolated hearts of rabbits and guinea-pigs. Br. J. Pharmacol. 73, 373-377 (1981)

5 Versailles, J.T., Verscheure, Y., Kim, A.L. and Pourrias, B.: Comparison between the ventricular fibrillation threshold of spontaneously hypertensive and normotensive rats-Investigation of antidysrhythmic drugs. J. Cardiovasc. Pharmacol. 4, 430-435 (1982)

6 Hellenbrecht, D. and Gortner, L.: Influence of isoprenaline and salbutamol on the threshold of electrically induced ventricular fibrillation in anaesthetized guinea-pigs. Naunyn Schmiedebergs Arch. Pharmacol. 287, 227-232 (1975)

7 Thormahlen, D. and Rohte, O.: Intracardiac electric stimulation in conscious rabbits. A new model for screening membrane-stabilizing antiarrhythmics. Naunyn Schmiedebergs Arch. Pharmacol. 317, 81-85 (1981)

8 Julian, D.G.: Toward preventing coronary death from ventricular fibrillation. Circulation 54, 360-364 (1976) 